\title{
Editorial
}

Nephrology

\section{The Extinguished BEACON of Bardoxolone: Not a Monday Morning Quarterback Story}

\author{
John A. Tayek ${ }^{\text {a }}$ Kamyar Kalantar-Zadeh ${ }^{\text {b-d }}$ \\ ${ }^{a}$ Divisions of Endocrinology and General Internal Medicine, ${ }^{b}$ Los Angeles Biomedical Research Institute at \\ Harbor-UCLA Medical Center, Torrance, Calif., ' Division of Nephrology and Hypertension, Harold Simmons \\ Center for Kidney Disease Research and Epidemiology, University of California Irvine Medical Center, \\ Orange, Calif., and d Department of Epidemiology, UCLA Fielding School of Public Health, Los Angeles, Calif., USA
}

The rise and fall of bardoxolone methyl, an oral antioxidant and anti-inflammatory modulator once hoped to be the ultimate silver bullet against diabetic nephropathy, is not a unique story in medicine. What was distinctive in this story, however, was the dramatically high level of enthusiasm about the miraculous effect of the drug after the publication of its phase II trial in chronic kidney disease (CKD) patients, known as the BEAM study [1]. In the said double-blind, randomized, placebo-controlled trial, 227 diabetic CKD patients (estimated glomerular filtration rate, eGFR, $20-45 \mathrm{ml} / \mathrm{min} / 1.73 \mathrm{~m}^{2}$ ) who had received placebo or bardoxolone at target doses of 25,75 , or $150 \mathrm{mg}$ daily for 24 weeks showed a significant rise in the mean eGFR of $+8.2,+11.4$, and $+10.4 \mathrm{ml} / \mathrm{min} / 1.73 \mathrm{~m}^{2}$, respectively, compared to placebo, and the improvements apparently persisted up to 52 weeks [1]. The main mechanism of action of bardoxolone was believed to be the antiinflammatory feature that was attributed to the activation of Nrf2, a ubiquitous transcription factor involved in the upregulation of cytoprotective genes, inhibition of NF- $\kappa \mathrm{B}$, and decreased oxidative stress [2].

The reported kidney function improvement in bardoxolone was remarkable, but so was the adverse event profile of the drug, which included worsening proteinuria, massive weight loss, muscle spasm, hypomagnese- mia, liver function disarrays, and gastrointestinal effects, among others [1] (table 1). The calculation of eGFR in the BEAM study was based on the level of serum creatinine, which is influenced by muscle mass and probably dietary meat intake $[3,4]$. A dramatic weight loss differential of 5-10 kg was observed in patients who received bardoxolone compared with placebo; to be exact, the bardoxolone weight loss was $7.7-10.1 \mathrm{~kg}$ compared to $2.4 \mathrm{~kg}$ in the placebo group $[3,5]$. In one study, weight loss in diabetic patients reduced serum creatinine from 2.0 to $1.5 \mathrm{mg} / \mathrm{dl}$ ( $\mathrm{p}<0.05$ ), and eGFR increased by $13 \mathrm{ml} / \mathrm{min}$ [6]. In another study on obesity, an $8 \%$ weight loss increased eGFR by $8.9 \mathrm{ml} / \mathrm{min}$ by means of reducing serum creatinine [7]. Similarly, fasting for Ramadan increased eGFR likely due to loss of muscle and/or a reduction in dietary meat intake [8]. In dialysis patients, serum creatinine is a robust correlate of muscle mass [4]. In the BEAM study, the $9 \%$ loss of weight, and likely skeletal muscle, probably reduced serum creatinine and increased eGFR by $8-11 \mathrm{ml} / \mathrm{min}$ [1]. The MDRD equation in this study uses serum creati-

J.A.T. is Professor in Residence of Medicine at the UCLA David Geffen School of Medicine and attending physician at the Harbor-UCLA Medical Center.

\section{KARGER}

E-Mail karger@karger.com

www.karger.com/ajn (c) 2013 S. Karger AG, Basel

0250-8095/13/0373-0208\$38.00/0
Kamyar Kalantar-Zadeh, MD, MPH, PhD

Harold Simmons Center for Chronic Disease Research and Epidemiology Los Angeles Biomedical Research Institute at Harbor-UCLA Medical Center 1124 West Carson Street, C1-Annex, Torrance, CA 90502 (USA)

E-Mailkamkal@ucla.edu 
nine, age, sex, and race to estimate GFR [9]. Forty-two to $61 \%$ of patients on bardoxolone in the BEAM study had muscle spasm reflecting potential muscle loss [1]. Interestingly, the quartile with the greatest increase in eGFR $(26.4 \mathrm{ml} / \mathrm{min})$ had the largest weight loss $(11.3 \mathrm{~kg})$ [1]. Whereas weight reduction should generally be considered favorable in overweight and obese diabetic patients, any unintentional weight loss is inevitably associated with some degree of loss of lean body mass, including skeletal muscles $[10,11]$. Hence, the said bardoxolone-associated weight loss may have led to muscle wasting with a subsequent decline in the serum creatinine level, leading to a misleadingly calculated rise in eGFR $[3,9]$, not to mention that muscle loss per se may be associated with poor outcomes in both CKD and the general population [12, 13].

Another dramatic and rather paradoxical complication of bardoxolone was an increase in urinary albumin excretion that paralleled the increase in eGFR in the BEAM study [1]. Bardoxolone has a structure similar to cyclopentenone prostaglandins, which can cause renal vasodilatation $[14,15]$. It is therefore possible that bardoxolone may have increased the eGFR by causing afferent arteriolar dilatation and increasing intraglomerular pressure. Indeed most of the effect of bardoxolone on the eGFR happened within the first 4 weeks of therapy [16]. This hemodynamic effect is in sharp contradistinction to the angiotensin-converting enzyme inhibitor-associated efferent arteriolar dilatation and may result in the shortterm rise in GFR, which is somewhat similar to what is seen in early stages of diabetic nephropathy, whereas in the long term the glomerular damage from increased intraglomerular pressure may lead to an accelerated decline in renal function [15]. Higher intraglomerular pressure may also explain the paradoxical increase in albuminuria observed in participants receiving bardoxolone in the BEAM study [1]. Indeed, the decrease in eGFR and albuminuria in the intervention groups 4 weeks after the study completion supports the said notion that the effect may have been from hemodynamic rather than anti-inflammatory factors [15]. Hence, bardoxolone could affect glomerular hemodynamics and possibly tubular function, and thus influencing eGFR without truly improving renal function.

It is important to note that only $42 \%$ of patients who were receiving $75 \mathrm{mg}$ per day and $25 \%$ of patients who were receiving $150 \mathrm{mg}$ per day bardoxolone in the phase II BEAM study were still receiving the assigned dose at the end of the study [16]. This low rate of compliance with the assigned dose was presumably due to an increased in- cidence of adverse effects and should have warned the investigators and consultants of the phase III BEACON trial (Bardoxolone Methyl Evaluation in Patients with CKD and Type 2 Diabetes: The Occurrence of Renal Events) that inflated adverse events and more unfavorable complications would be expected with a phase III trial.

The unexplained hypomagnesemia developed in a dose-dependent manner in $26 \%$ of bardoxolone-treated patients compared with $5 \%$ of patients in the placebo group [17]. Ironically, magnesium has anti-inflammatory and anti-oxidant properties, and it was warned that hypomagnesemia, a predictor of worse CKD progression, might abrogate the long-term beneficial effects of bardoxolone [17]. Other side effects of bardoxolone included gastrointestinal symptoms and liver function abnormalities, as well as muscle spasm [1]. The latter may be reminiscent of structural damage to the muscle fibers and myocytes during the muscle wasting or the observed weight loss. Moreover, among the yet-to-be-reported BEACON study, there were apparently significant numbers of deaths and heart failure in the bardoxolone group [18], which may be due to collective effects of the above-mentioned deleterious events or from additional adverse effects of the drug such as loss of cardiac muscle.

In their rush to move forward with the phase III trial, the investigators argued that no change in 24-hour urinary creatinine excretion was observed after 8 weeks of treatment with bardoxolone in a preliminary study [19]. It was never explained as to why the massive weight loss and the paradoxical increase in proteinuria happened, nor were any of the other side effects adequately examined (table 1). The investigators chose to ignore these warnings $[3,5,15-17]$ and to proceed with the trial of long-term outcomes (NCT01351675). BEACON had begun in June 2011, aiming to recruit 2,000 patients with CKD or type 2 diabetes and test whether bardoxolone delayed their progression to end-stage renal disease versus placebo, as described in this issue of the American Journal of Nephrology [18]. However, the BEACON study was stopped on the recommendation of its independent datamonitoring committee, which apparently reported the safety imbalance between the active and placebo arms. Reata (Irving, Tex., USA), the manufacturer of bardoxolone methyl in the USA, has not yet disclosed any detailed information about the nature of the serious adverse events or how many deaths happened in each arm, although these data will eventually be reported. Reata also announced that all other studies of bardoxolone in CKD would also be halted. According to clinicaltrials.gov there 
Table 1. Potential adverse effects of bardoxolone methyl in CKD patients

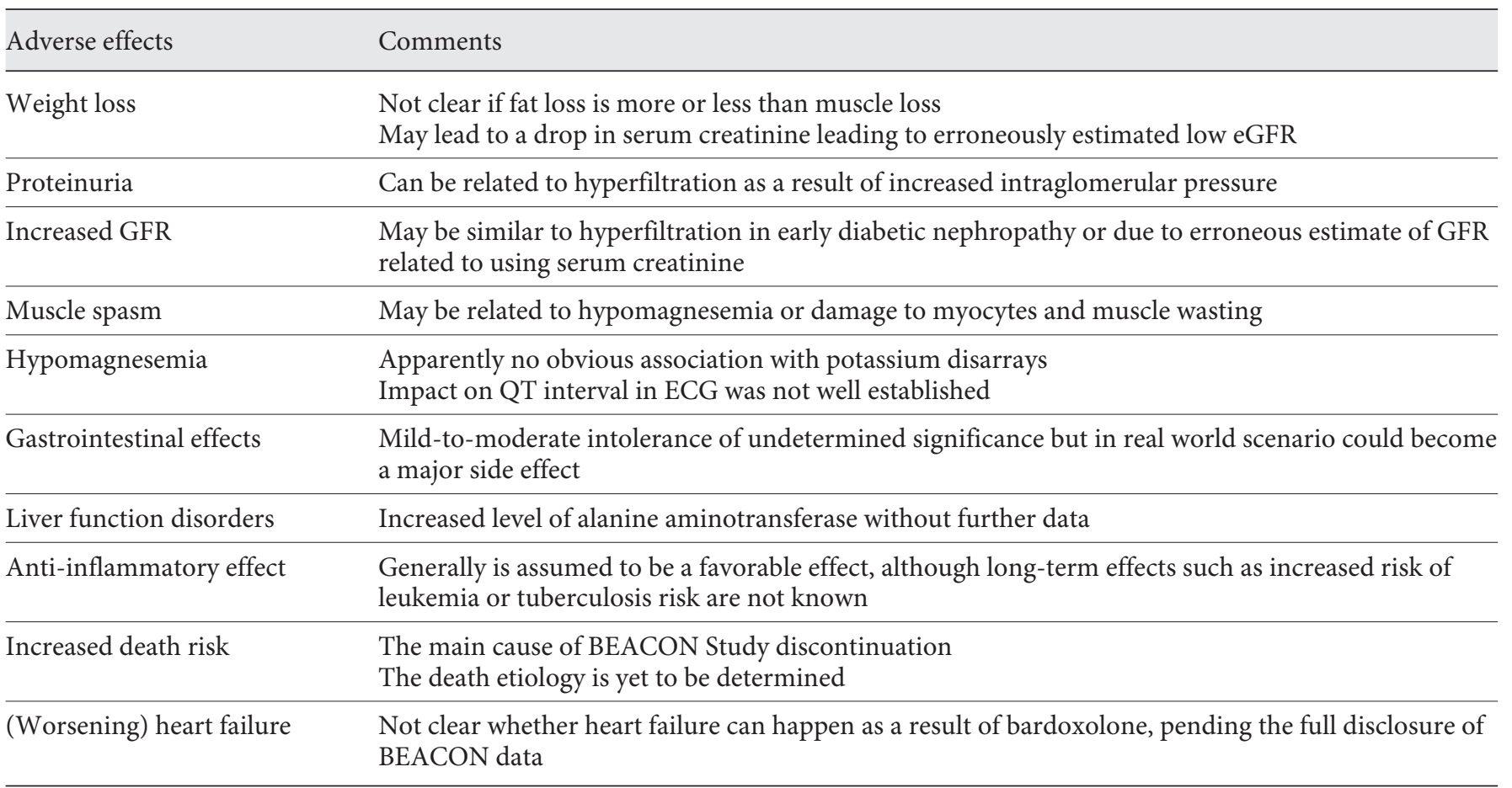

were several ongoing phase I or II studies, including a large phase II trial in 180 volunteers to test the effect of bardoxolone on cardiovascular measures. Prior to October 2012, two phase I and three phase II studies have been completed in a total of 474 subjects according to clinicaltrials.gov.

Undoubtedly, CKD associated with type 2 diabetes is the leading cause of kidney failure both in the United States and globally. Inflammation and oxidative stress contribute to disease progression. The effect of bardoxolone on diabetic nephropathy was obviously too good to be true, and the adverse event profile was overwhelming. Echoing the righteous criticisms voiced back then $[3,5$, 15-17]. This is not a mere 'Monday morning quarterback' story but this is to reiterate that there were legitimate criticisms from experts who were clearly capable of second guessing adverse outcomes and the high failure likelihood of the BEACON study, given clear data from the BEAM study. The valuable lesson is that the enthusiasm and hope for ultimate cure of diabetic nephropathy should not cloud our judgment when designing and conducting future trials, or similar negative outcomes can be observed with any trial where the investigator chose to ignore the prior signs and loud warnings [20].

\section{Acknowledgment}

The study was supported by research grants from the National Institute of Diabetes, Digestive and Kidney Disease of the National Institutes of Health (R01-DK078106, R21-DK077341 and K24DK091419) and a philanthropic grant from Mr. Harold C. Simmons.

\section{Disclosure Statement}

K.K.-Z. has received honoraria and/or grants from Abbott, Amgen, DaVita, Fresenius, Genzyme, Otsuka, Shire, and Vifor, the manufacturers of drugs or devices and/or providers of services for CKD patients.

References Pergola PE, Raskin P, Toto RD, Meyer C),
Huff JW, Grossman EB, Krauth M, Ruiz S, Audhya P, Christ-Schmidt H, Wittes J, Warnock DG: Bardoxolone methyl and kidney function in CKD with type 2 diabetes. $\mathrm{N}$ Engl J Med 2011;365:327-336.

$\checkmark 2$ Reisman SA, Chertow GM, Hebbar S, Vaziri ND, Ward KW, Meyer CJ: Bardoxolone methyl decreases megalin and activates nrf2 in the kidney. J Am Soc Nephrol 2012;23: 1663-1673.

Tayek/Kalantar-Zadeh 
3 Patel SS, Molnar MZ, Tayek JA, Ix JH, Noori $\mathrm{N}$, Benner D, Heymsfield S, Kopple JD, Kovesdy CP, Kalantar-Zadeh K: Serum creatinine as a marker of muscle mass in chronic kidney disease: results of a cross-sectional study and review of literature. J Cachexia Sarcopenia Muscle 2012, E-pub ahead of print.

-4 Noori N, Kovesdy CP, Bross R, Lee M, Oreopoulos A, Benner D, Mehrotra R, Kopple JD, Kalantar-Zadeh K: Novel equations to estimate lean body mass in maintenance hemodialysis patients. Am J Kidney Dis 2011;57: 130-139.

5 Rogacev KS, Bittenbring JT, Fliser D: Bardoxolone methyl, chronic kidney disease, and type 2 diabetes. N Engl J Med 2011;365:17451746 , author reply $1746-1747$.

-6 Saiki A, Nagayama D, Ohhira M, Endoh K, Ohtsuka M, Koide N, Oyama T, Miyashita Y, Shirai K: Effect of weight loss using formula diet on renal function in obese patients with diabetic nephropathy. Int J Obes (Lond) 2005; 29:1115-1120.

7 Straznicky NE, Grima MT, Lambert EA, Eikelis N, Dawood T, Lambert GW, Nestel PJ, Masuo K, Sari CI, Chopra R, Mariani JA, Schlaich MP: Exercise augments weight loss induced improvement in renal function in obese metabolic syndrome individuals. J Hypertens 2011;29:553-564.

8 Bernieh B, Al Hakim MR, Boobes Y, Abu Zidan FM: Fasting Ramadan in chronic kidney disease patients: clinical and biochemical effects. Saudi J Kidney Dis Transpl 2010;21: 898-902.
-9 Kalantar-Zadeh K, Amin AN: Toward more accurate detection and risk stratification of chronic kidney disease. JAMA 2012;307: 1976-1977.

10 Kalantar-Zadeh K, Streja E, Molnar MZ, Lukowsky LR, Krishnan M, Kovesdy CP, Greenland S: Mortality prediction by surrogates of body composition: an examination of the obesity paradox in hemodialysis patients using composite ranking score analysis. Am J Epidemiol 2012;175:793-803.

11 Kalantar-Zadeh K, Streja E, Kovesdy CP, Oreopoulos A, Noori N, Jing J, Nissenson AR, Krishnan M, Kopple JD, Mehrotra R, Anker SD: The obesity paradox and mortality associated with surrogates of body size and muscle mass in patients receiving hemodialysis. Mayo Clin Proc 2010;85:991-1001.

$12 \mathrm{Ix} \mathrm{JH}$, de Boer IH, Wassel CL, Criqui MH, Shlipak MG, Whooley MA: Urinary creatinine excretion rate and mortality in persons with coronary artery disease: the Heart and Soul Study. Circulation 2010;121:1295-1303.

13 Noori N, Kopple JD, Kovesdy CP, Feroze U, Sim JJ, Murali SB, Luna A, Gomez M, Luna C, Bross R, Nissenson AR, Kalantar-Zadeh K: Mid-arm muscle circumference and quality of life and survival in maintenance hemodialysis patients. Clin J Am Soc Nephrol 2010;5: 2258-2268.

14 Lee SJ, Johnson JG, Smith CJ, Hatch FE: Renal effects of prostaglandin $\mathrm{A} 1$ in patients with essential hypertension. Kidney Int 1972;1: 254-262.
15 Upadhyay A, Sarnak MJ, Levey AS: Bardoxolone methyl, chronic kidney disease, and type 2 diabetes. N Engl J Med 2011;365:1746, author reply 1746-1747.

16 McMahon GM, Forman JP: Bardoxolone methyl, chronic kidney disease, and type $2 \mathrm{di}$ abetes. N Engl J Med 2011;365:1746, author reply $1746-1747$.

17 Van Laecke S, Vanholder R: Bardoxolone methyl, chronic kidney disease, and type $2 \mathrm{di}-$ abetes. N Engl J Med 2011;365:1745, author reply 1746-1747.

18 de Zeeuw D, Akizawa T, Agarwal R, Audhya P, Bakris GL, Chin M, Krauth M, Lambers Heerspink HJ, Meyer CJ, McMurray JJ, Parving $\mathrm{H}-\mathrm{H}$, Pergola PE, Remuzzi G, Toto RD, Vaziri ND, Wanner C, Warnock DG, Wittes J, Chertow GM: Bardoxolone methyl evaluation in patients with chronic kidney disease and type 2 diabetes: the occurrence of renal events (BEACON): rationale and trial design. Am J Nephrol 2013, in press.

19 Pergola PE, Krauth M, Huff JW, Ferguson DA, Ruiz S, Meyer CJ, Warnock DG: Effect of bardoxolone methyl on kidney function in patients with T2D and stage 3b-4 CKD. Am J Nephrol 2011;33:469-476.

20 Chertow GM, Block GA, Correa-Rotter R, Drueke TB, Floege J, Goodman WG, Herzog CA, Kubo Y, London GM, Mahaffey KW, Mix TC, Moe SM, Trotman ML, Wheeler DC, Parfrey PS: Effect of cinacalcet on cardiovascular disease in patients undergoing dialysis. $\mathrm{N}$ Engl J Med 2012;367:2482-2494. 